\title{
RESEARCH
}

Open Access

\section{Predictors of prolonged length of hospital stay and in-hospital mortality among adult patients admitted at the surgical ward of Jimma University medical center, Ethiopia: prospective observational study}

\author{
Gosaye Mekonen Tefera ${ }^{1 *}$ D, Beshadu Bedada Feyisa ${ }^{2}$, Gurmu Tesfaye Umeta ${ }^{1}$ and Tsegaye Melaku Kebede ${ }^{3}$
}

\begin{abstract}
Background: Data regarding prolonged length of hospital stay (PLOS) and in-hospital mortality are paramount to evaluate efficiency and quality of surgical care as well as for rational resource utilization, allocation, and administration. Thus, PLOS and in-hospital mortality have been used as a surrogate indicator of satisfactory treatment outcome and efficient utilization of resources for a given health institution. However, there was a scarcity of data regarding these issues in Ethiopia. Therefore, this study aimed to assess treatment outcome, length of hospital stay, in-hospital mortality, and their determinants.

Methods: Health facility-based prospective observational study was used for three consecutive months among adult patients hospitalized for the surgical case. Socio-demographic, clinical history, medication history, in-hospital complications, and overall treatment outcomes were collected from the medical charts' of the patients, using a checklist from the day of admission to discharge. PLOS is defined as hospital stay $>75$ th percentile ( $\geq 33$ days for the current study). To identify predictor variables for both PLOS and in-hospital mortality, multivariate logistic regression was performed at $p$-value $<0.05$ using SPSS version 20 . Written informed consent was sought and secured.

Results: Of 269 study participants, 91.8\% were improved and discharged. PLOS was recorded in 25.3\%; at least 33 days of hospital stay. Overall in-hospital mortality was 4.8\%; which is equal to an incidence rate of 0.00193 per person-days, 5.2\% in-hospital sepsis, and $2.6 \%$ of Hospital-acquired pneumonia (HAP), during their hospital stay. After adjusting for other factors; female gender ( $p=0.003$ ), emergency admission ( $p=0.015)$, presence of Poly-pharmacy $(p=0.017)$, and presence of sepsis $(p=0.006)$ were found to be independent predictors for in-hospital mortality. On top of this, female gender $(p=0.026)$, patients who was paid by government $(p=0.007)$, burn-related surgery $(p=0.049)$, presence of cancer $(p=0.027)$, $>2$ antibiotic exposure $(p<0.0001)$, and waiting for surgery for $>7$ days $(p<0.0001)$ were independent predictors for PLOS.

(Continued on next page)
\end{abstract}

\footnotetext{
* Correspondence: Gosi2010pharma@gmail.com

'Department of Pharmacy, Clinical Pharmacy Unit, Ambo University, Ambo, Ethiopia

Full list of author information is available at the end of the article
}

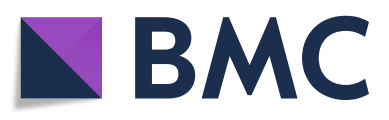

( ) The Author(s). 2020 Open Access This article is licensed under a Creative Commons Attribution 4.0 International License, which permits use, sharing, adaptation, distribution and reproduction in any medium or format, as long as you give appropriate credit to the original author(s) and the source, provide a link to the Creative Commons licence, and indicate if changes were made. The images or other third party material in this article are included in the article's Creative Commons licence, unless indicated otherwise in a credit line to the material. If material is not included in the article's Creative Commons licence and your intended use is not permitted by statutory regulation or exceeds the permitted use, you will need to obtain permission directly from the copyright holder. To view a copy of this licence, visit http://creativecommons.org/licenses/by/4.0/ The Creative Commons Public Domain Dedication waiver (http://creativecommons.org/publicdomain/zero/1.0/) applies to the data made available in this article, unless otherwise stated in a credit line to the data. 


\begin{abstract}
(Continued from previous page)
Conclusion: In-hospital mortality rate was almost comparable to reports from developing countries, though it was higher than the developed countries. However, the length of hospital stay was extremely higher than that of reports from other parts of the world. Besides, different socio-demographic, health facility's and patients' clinical conditions (baseline and in-hospital complications) were identified as independent predictors for both in-hospital mortality and PLOS. Therefore, the clinician and stakeholders have to emphasize to avoid the modifiable factors to reduce in-hospital mortality and PLOS in the study area; to improve the quality of surgical care.
\end{abstract}

Keywords: In-hospital mortality, Prolonged length of hospital stay, Predictors, Surgery, Ethiopia

\section{Introduction}

There was no consistent cutoff point for prolonged length of hospital stay (PLOS). However, it was defined as the total bed-days occupied by a patient during hospitalization for more than the expected length of stay for a certain procedure [1]. The length of hospital stay is often used as a measure of the quality of care and efficient resource utilization; as patients with PLOS extremely account for the consumption of more hospital resources, hospital-acquired infection (HAI), more complications, high mortality rate, denies critically ill patients timely access to treatment and contributing to capacity shortage [1-3].

Nevertheless, PLOS alone is imperfect indicators for the quality of surgical care [4]. Thus, information related to the length of hospital stay, postoperative complications, number of HAI, and mortality is paramount to evaluate efficiency and quality of surgical care [1-4]. As a result of high mortality and complication rates of major surgical procedures in low and middle-income countries (LMICs), surgical safety should be a global concern [5].

Admission with surgery case by itself is found to be one of the causes that contribute to PLOS in LMICs [1]. This, in turn, contributes significantly to extra cost, morbidity, and mortality $[1,6,7]$. Therefore, knowledge of the factors contributing to PLOS and mortality among patients treated with the surgery is an important factor to be considered as a quality of surgical care indicators [8]. Worldwide, 4.8 billion people devoid of access to safe and quality surgical care, due to lack of infrastructure, equipment, and personnel, especially in LMICs [9]. Thus, among patients undergoing surgery, the mortality rates were higher for LMICs $[10,11]$, for instance, the postoperative death was 2times higher than the global deaths in Africa [12].

Similar to other countries, Ethiopia has been striving to meet the gaps in surgical care, through innovative methods for surgical system development with Saving Lives through Safe Surgery; designed to improve access to safe, essential and emergency surgical and anesthesia care across all levels of the healthcare system [13]. Thus, to early identify the area that needs focus, and for rational allocation and use of the available resources in the country, assessing the surrogate indicators of quality of surgical care such as PLOS, postoperative complications, number of HAI and mortality rate is mandatory. Besides, for the Hospital and stakeholders to take action, the critical step is identifying the status of these quality indicators ahead of preparing for the action plan. However, a study was lacking regarding the predictors of PLOS and in-hospital mortality in the surgical wards of Ethiopia [11]. Even, in developed countries, there were few reports of predictors' of mortality and PLOS with heterogeneous study results, study population, and type/ discipline of surgery with retrospective study design [1]. Therefore, this study aimed to assess treatment outcome, length of hospital stay, in-hospital mortality, and their predictors among adult patients undergoing the surgical procedure.

\section{Methods and participants \\ Study area, period and design}

The study was conducted from April 24 to July 24/2017 at Jimma University Medical Center (JUMC). The Surgery department has been run by 8 seniors, 43 residents, 5 general practitioners, and medical interns as rotation [14]. Health facility-based prospective observational study was used. Study populations were patients who were admitted to the surgical ward with either elective or emergency admission during the study period with inclusion criteria.

\section{Inclusion and exclusion criteria}

Patients admitted at the surgical ward at the time of data collection but, did not undergo a surgical procedure at the time of initial data collection and ages of $\geq 18$ years were included. Those who were not willing to participate, patients only on a topical antibiotic for superficial wound care and infected or non-infected burn wound, a trauma-related wound that needs the only debridement or wound care were excluded. Also, patients who were referred or left against medical advice (LAMA) ahead of surgery were excluded from the final analysis. 


\section{Study variables}

\section{Dependent variables}

In-hospital mortality and length of hospital stay.

\section{Independent variables}

Age, sex, residence, Surgical site infection, types of surgery, type of wound classification, American society of anesthesiology (ASA) class, co-morbid conditions and types, smoking status, appropriateness of surgical antimicrobial prophylaxis (SAP) use, length of hospital stay before surgery, duration of operation, Charlson comorbidity Index, HAI, sepsis, blood loss during operation, type of surgical admission (emergency or elective), diagnosis and poly-pharmacy.

\section{Sample size and sampling technique}

Sample size (n) was calculated by using a single population proportion formula [15], to determine the minimum sample size required for estimation of true proportion as follow:

$$
n 1=Z(\partial / 2)^{2} * \frac{P(1-P)}{W^{2}}=1.96^{2} * \frac{(0.94 * 0.06)}{0.05^{2}}=87 \text { for mortality rate }
$$

Where; $\mathrm{P}$ is the proportion of mortality rate of 0.06 from reference [16], $\mathrm{Z}$ is level of confidence $=1.96$ with $95 \% \mathrm{CI}, \mathrm{N}$ is the size of the population that the sample is to represent $=1265$ per 3 months, $\mathrm{W}$ is the margin of error $=5 \%$; Since $N$ is less than 10,000 correction formula was applied [15]:

$$
\begin{aligned}
n f & =\frac{n}{1+\frac{n}{N}} \\
& =81, \text { then } 5 \% \text { non-response rate was added } \\
& =85
\end{aligned}
$$

Surveillance by using consecutive type of sampling technique, data was collected from 269 patients available within 3 months to increase its robustness.

\section{Data collection instrument, process, and management}

Semi-structured questionnaires (English version) were used with a slight modification of the tool used by the previously published research [14]. These questionnaires contain five parts, part I (socio-demographic characteristics), part II (patient's clinical information and Charlson co-morbidity index), part III (patient's medication information), and Part IV (appropriateness of SAP use) and part $\mathrm{V}$ (overall treatment outcome) of the study participants.

Initially, the patient's chart was reviewed for inclusion and exclusion criteria at the time of admission. Then the 4 data collectors (2 post-graduate clinical pharmacists and 2 surgical nurses) collected information using a pretested checklist. The Centers for Disease Control and Prevention $(\mathrm{CDC})$ wound class was first classified by attending physician and rechecked by one senior surgery resident independently and the discrepancy was solved by communicating with the attending physician. It was done only for the primary surgical procedure, not for the 2nd or 3rd [14]. Then the data collectors reviewed and filled patient's information from the notes of anesthesia and medical (physicians' orders and nurses' notes) and patient interviews (only consent and sociodemographic information). Case finding: overall treatment outcome (hospital-acquired pneumonia/ HAP, sepsis, in-hospital mortality, and length of hospital stay) of patients were measured prospectively.

Data quality assurance, processing, and statistical analysis Data were coded, checked for consistency and entered into EpiData manager version 4. Then the data was exported to SPSS version 20 for analysis. Percentage and frequency were used for categorical variables. Continuous variables were expressed using measures of central tendency and variability such as mean and standard deviation. The model fitness for the variables was evaluated by the Hosmer-Lemeshow goodness of fit test and the $p$-value was found to be 0.245 in binary analysis and $p>$ 0.05 for all variables in multivariate analysis. Variables with a significance level of $P<0.25$ in binary logistic regression were selected as a candidate for multivariate analysis, then significance level was considered at a $p$ value of $<0.05$.

\section{Ethical consideration and participants' consent}

The letter of allowance to proceed with the study was sought under protocol number IHRPGQ/103/207 from Jimma University, Institute of Health. The patients were requested for written informed consent. The confidentiality of the patients' was secured. PLOS is defined as the proportion of the study participants with hospital stay greater than 75th percentile (in JUMC it was found to be $\geq 33$ days) for the entire study population [1].

\section{Results \\ Socio-demographic characteristics of the study participants}

Two hundred sixty-nine (operated) patients were included in the study. The mean $( \pm \mathrm{SD})$ age of the participant was $41.95 \pm 17.76$ and the majority of the study participants were male (66.5\%), and earn less or equal to 6000 Ethiopian birrs (90.7\%). Regarding the cost of health care coverage, the majority $(82.9 \%)$ were classified as a self payer (Table 1 ). 
Table 1 Socio-demographic characteristics of the study participants at JUMC, Ethiopia $(N=269)$

\begin{tabular}{llll}
\hline Variables & Categories & Frequency & Percentage \\
\hline Age (year) & mean age \pm SD & $41.95 \pm 17.76$ (18 to 90) \\
Sex & Male & 179 & 66.5 \\
& Female & 90 & 33.5 \\
Monthly income & no constant income & 47 & 17.5 \\
& $<1500$ & 95 & 35.3 \\
& $1500-6000$ & 102 & 37.9 \\
Health cost coverage $^{\text {a }}$ & $>$ Self-payment & 223 & 9.3 \\
& Free (government) & 46 & 17.1 \\
\hline
\end{tabular}

a - the majority (21.3\%) of patients with no constant income were paid by the government or got free service at JUMC

\section{Clinical characteristics of the study participants}

Of the total (269), $40.9 \%$ of the study participants had a co-morbid condition. Of which 59 (21.9\%) had a chronic type of co-morbidity, 46 (17.1\%) oncologic related condition, 48 (17.8\%) trauma-related condition, and 14 (5.2\%) burn-related surgery. The most common type of surgical discipline carried out at the study area was related to the upper and lower gastrointestinal tract (30.5\%) followed by skin and deep tissue (incision, drainage, local excision) $(23.0 \%)$. The mean \pm SD hospital stay before surgery, after surgery and overall hospital stay, was $7.74 \pm$ $14.51,17.61 \pm 16.87$ and $25.35 \pm 21.42$ days respectively, as well as the majority (59.9\%) of the patients stayed for at least 15 days in the hospital (Table 2).

\section{Incidence of hospital-acquired infection (sepsis \& HAP)} and overall clinical outcome of the study participants

Overall clinical out-come of study, participants were improved in about $(91.8 \%)$ of cases followed by death in Hospital in about $13(4.8 \%)$ of cases. Among the study participants, $5.2 \%$; which is equal to a sepsis incidence rate of 0.00208 per person-days or 2.08 per 1000 person-days and $2.6 \%$ Hospital-acquired pneumonia (HAP); which is equal to an incidence rate of 0.00104 per person-days or 1.04 per 1000 person-days developed sepsis and HAP respectively, during their hospital stay. Besides, even though the majority of the patient's treatment outcome was good (improved), the mortality rate was also high (4.8\%); which is equal to an incidence rate of 0.00193 per person-days or 1.93 mortality rate per 1000 person-days. The prolonged length of overall hospital stay (PLOS) was 25.3\%; at least 33 days of hospital stay (Table 2 and Fig. 1).

\section{Predictors of in-hospital mortality and prolonged length of hospital stay (PLOS)}

Knowing the predictors of in-hospital death and PLOS is essential in reducing patient-related harm. In turn, it allows us to give special attention to the hope of improving surgery-related treatment outcomes. Hence, the factors that were candidate for multivariate analysis; ( $p$ value $<0.25)$ were: gender of female $(p$ value $=0.036)$, ASA class III-IV ( $p$ value of 0.191 ), Co-morbid condition ( $p$ value $=0.007)$, emergency type of admission $(\mathrm{p}$ value $=$ $0.008)$, CDC wound class II-IV ( $\mathrm{p}$ value $=0.134$ ), poly pharmacy status $(p$ value $=0.001$ ), Amount of blood loss during surgery $(p=0.187)$, Right selection + dose+ timing + duration + route of SAP ( $p$ value $=0.025)$, total antibiotic exposure in hospital of $>2(p<0.015)$, in-Hospital sepsis in (p value $<0.0001$ ) for in-hospital mortality while, Female gender $(p<0.0001)$, smoking status $(p=0.076)$, health care cost coverage $(p=0.023)$, burn related surgery/ skin graft $(p=0.036)$, presence of cancer $(p=0.018)$, presence of trauma $(p=0.060)$, type of admission $(\mathrm{p}=0.023)$, inhospital SSI $(p=0.035)$, duration of surgery $(p=0.083)$, appropriate use of SAP $(p=0.105)$, total number of antibiotic exposure $(p<0.0001)$, ASA class $(p=0.193)$, CDC wound class $(\mathrm{p}=0.047)$, before surgery LOS (days) $(\mathrm{p}<0.0001)$, and number of co-morbidity $(p=0.248)$ for PLOS among study participants (Tables 3 and 4).

A stepwise backward multivariate logistic regression analysis showed that, study participants with female gender were about 12 times more likely to have a negative outcome (death) relative to male gender $[\mathrm{AOR}=11.50$ $(2.33-56.81)$ at $95 \% \mathrm{CI}$; p value $=0.003]$. Emergency surgery increase the probability of in-hospital death by about 9 times than elective surgery [AOR $=8.58(1.52-$ 48.38 ) at $95 \% \mathrm{CI} ; p$ value $=0.015$ ]. Presence of Polypharmacy and in-hospital sepsis increase the risk of death by about 6 times $[\mathrm{AOR}=5.94(1.37-25.80)$ at $95 \%$ $\mathrm{CI} ; \mathrm{p}$ value $=0.017$ and 12 times $[\mathrm{AOR}=11.65(2.02-$ $67.08)$ at $95 \% \mathrm{CI} ; p$ value $=0.006]$, respectively than patients who devoid of poly-pharmacy and sepsis (Fig. 2).

On the other hand, patients with female gender were 2 times more likely to have PLOS [AOR $=2.105$ (1.0934.053 ) at $95 \%$ C.I; $\mathrm{p}=0.026$ ], patients who was paid by government were 3 times more likely to have PLOS [AOR $=3.037(1.362-6.770)$ at $95 \%$ C.I; $\mathrm{p}=0.007$ ], burn related surgery was about 3 times more likely to increase risk of PLOS $[\mathrm{AOR}=3.436(1008-11.720)$ at $95 \%$ C.I; $\mathrm{p}=$ 0.049], and presence of cancer increases the likelihood of PLOS by about 3 times [AOR $=2806(1.125-6.996)$ at $95 \%$ C.I; $\mathrm{p}=0.027$. Besides, $>$ two antibiotics exposure during hospital stay increases the chance of PLOS by about 4 times $[\mathrm{AOR}=3.873(1.909-7.857)$ at $95 \%$ C.I; $\mathrm{p}<0.0001]$, and awaiting for surgery for $>7$ days increases the probability of PLOS by about 4 times [AOR $=4.136(2.075-$ $8.246)$ at $95 \%$ C.I; $\mathrm{p}<0.0001$ ] relative to their counterpart for each of variables respectively (Fig. 3).

\section{Discussion}

This was a 3-month health facility-based prospective observational study to assess treatment outcome (in- 
Table 2 Clinical characteristics and in-hospital complication of the study participants at JUMC, Ethiopia $(N=269)$

\begin{tabular}{|c|c|c|c|}
\hline Variables & Categories & Frequency & Percentage \\
\hline \multirow[t]{2}{*}{ Co-morbid condition } & Yes & 110 & 40.9 \\
\hline & No & 159 & 59.1 \\
\hline \multirow[t]{3}{*}{ Number of co-morbidity } & No co-morbid & 159 & 59.1 \\
\hline & 1-2 co-morbid & 98 & 36.4 \\
\hline & $\geq 3$ co-morbid & 12 & 4.5 \\
\hline \multirow[t]{2}{*}{ Types of co-morbidity } & Non-chronic disease & 210 & 78.1 \\
\hline & Chronic disease & 59 & 21.9 \\
\hline \multirow[t]{2}{*}{ Oncologic condition } & No & 223 & 82.9 \\
\hline & Yes & 46 & 17.1 \\
\hline \multirow[t]{2}{*}{ Trauma-related condition } & No & 221 & 82.2 \\
\hline & Yes & 48 & 17.8 \\
\hline \multirow[t]{2}{*}{ Burn related surgery/skin graft ${ }^{a}$} & No & 255 & 94.8 \\
\hline & Yes & 14 & 5.2 \\
\hline \multirow[t]{8}{*}{ Types of surgical discipline } & upper and lower GIT & 82 & 30.5 \\
\hline & Breast & 6 & 2.2 \\
\hline & Urology & 41 & 15.2 \\
\hline & Cardiothoracic & 10 & 3.7 \\
\hline & Billary tract & 5 & 1.9 \\
\hline & head and neck & 40 & 14.9 \\
\hline & skin and deep tissue (incision, drainage, local excision) & 62 & 23.0 \\
\hline & Other ${ }^{\mathrm{b}}$ & 23 & 8.6 \\
\hline \multirow[t]{4}{*}{ The overall length of hospital stay } & $\leq 7$ days & 35 & 13.0 \\
\hline & 8 to 15 days & 73 & 27.1 \\
\hline & $>15$ days & 161 & 59.9 \\
\hline & Mean $\pm S D$ (minim- maximum) & \multicolumn{2}{|c|}{$25.35 \pm 21.42$ ( 1 to 127 days) } \\
\hline \multirow[t]{4}{*}{ After operation length of hospital stay } & $\leq 7$ days & 68 & 25.3 \\
\hline & $>7$ to $\leq 15$ days & 101 & 37.5 \\
\hline & $>15$ days & 100 & 37.2 \\
\hline & Mean $\pm S D$ (minim- maximum) & \multicolumn{2}{|c|}{$17.61 \pm 16.87$ (0 to 120 days) } \\
\hline \multirow[t]{4}{*}{ Before operation length of hospital stay } & $\leq 7$ days & 198 & 73.6 \\
\hline & $>7$ to $\leq 15$ days & 27 & 10.0 \\
\hline & $>15$ days & 44 & 16.4 \\
\hline & Mean $\pm S D$ (minim- maximum) & \multicolumn{2}{|c|}{$7.74 \pm 14.51$ ( 0 to 112 days) } \\
\hline Mortality rate & The incidence rate of death per person-days & \multicolumn{2}{|c|}{0.00193 per person-days } \\
\hline In-hospital sepsis & Incidence rate per person-days & \multicolumn{2}{|c|}{0.00208 per person-days } \\
\hline HAP & Incidence rate per person-days & \multicolumn{2}{|c|}{0.00104 per person-days } \\
\hline
\end{tabular}

N.B: GIT- gastrointestinal tract, HAP- Hospital-acquired pneumonia, ${ }^{a}$ was more in female (7.8\%) than male (3.9\%), ${ }^{\mathrm{b}}$ - varicose vein, Hematoma, Gangrene, compartment syndrome, Contracture, and septic arthritis.

hospital mortality \& PLOS with 75th percentile or $\geq 33$ days) and their predictors among adult patients at the surgery ward of JUMC had found a high rate of inhospital mortality and PLOS among hospitalized patients. The socio-demographic and clinical characteristics (baseline and in-hospital complications were found to be independent predictors for both in-hospital death and PLOS for 269 patients included in the study.

Among the study participant, $5.2 \%$ in-hospital sepsis incidence rate and 2.6\% HAP were identified during their Hospital stay in JUMC. The postoperative HAP in JUMC is lower than the study done on intra-abdominal 


\section{Overall treatment outcomes of surgical patients at JUMC, 2017}

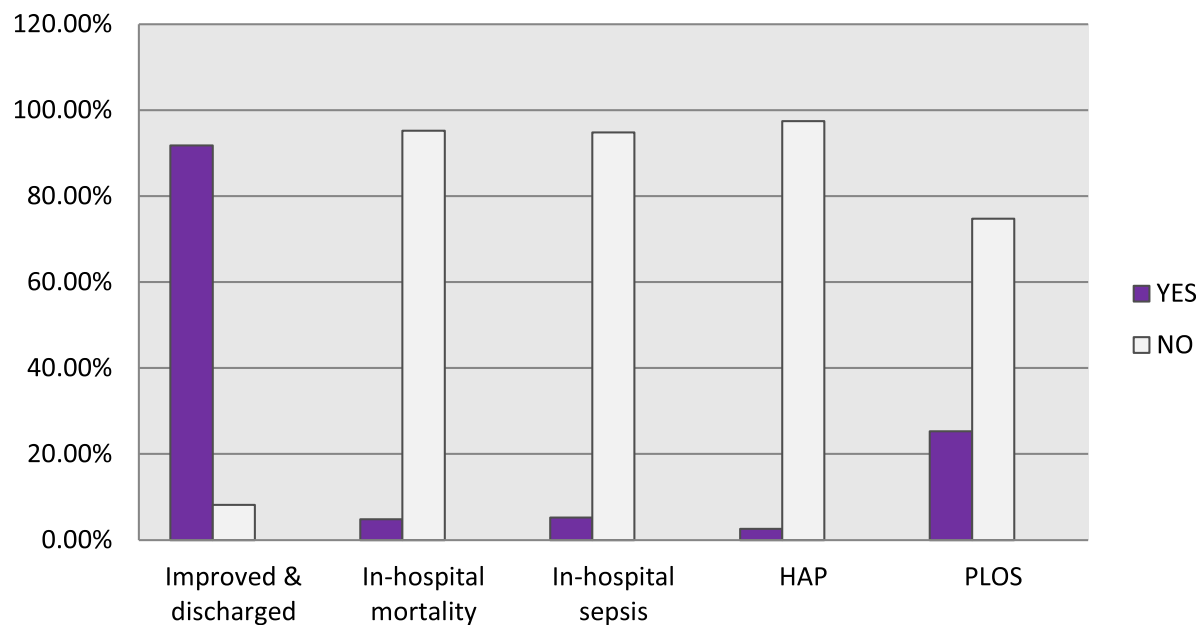

Fig. 1 Overall treatment outcomes of patients admitted at the surgical ward of JUMC, Ethiopia $(N=269)$. N.B: PLOS- prolonged length of hospital stay ( $\geq 33$ days), HAP- Hospital acquired pneumonia

surgical patients (10.7\%) and increased risk of mortality by 10 fold [17]. The reason for this difference might be that patients with gastro-intestinal surgery are more prone to aspiration pneumonia and high rate of HAP, especially gastrostomy even than other gastro-intestinal surgery (decreases gastric acid then increase bacterial colony thus, increase risk of HAP). The surgical injury/ procedure is one factor that increases the risk of HAI (HAP, sepsis, or septic shock) which in turn increases the risk of in-hospital death among patients undergoing surgery [17, 18]. Another study added postoperative complications occurred in $18.2 \%$; infection was the most common complication and $2.1 \%$ of mortality rate [12]. Therefore, the hospital and department of surgery of JUMC should take action to reduce prolonged hospitalization as well as a HAP like bloodstream infection or sepsis and HAP.

Regarding treatment outcome in terms of hospital stay, the mean overall hospital stay was $25.06 \pm 21.415$ days and in-hospital mortality was 13 (4.8\%). However, hospital stay was higher, compared to study from Gondar, a median of $14.2 \pm 8.4$ days, also, the median hospital stay was 4 days in African Hospitals [4], and 6 days median stay [2]. Additionally, in Singapore [19] median hospital stay was 7 days which was extremely lower than JUMC; which needs a revision of health care service at the study area.

while the clinical outcome was almost comparable with a study from Gonder, Ethiopia; improved (90.4\%) and died (6.0\%) [16], but, less than the study done in Tikur Anbessa Specialized Hospital; 7.0\% overall death per procedure [11]. In St Paul General Specialized Hospital and Gondar University Hospital, Ethiopia after the onset of symptoms, delay of acute abdomen and abdominal trauma for more than 3 days before operation resulted in $67 \%$ death [20]. Other studies also reported in-hospital death rate of 3.4\% [8], 2.2\% [21] however, the in-hospital mortality rate of $14.7 \%$ [22] was higher than our study result. The reason for this difference was because the later study included older patients ( $>80$ years unlike that of $>18$ years). On the other hand, the mortality rate was reported from 2.3 to $48.5 \%$ for patients undergoing a different type of surgery and heterogeneous study population as well as different severity [8, 23-26]; indeed the death rate is high for low-income countries because of different reason $[10,12]$, for instance, in America, the overall mortality rate was $0.28 \%$ [27].

PLOS might be due to prolonged waiting for surgery (mean of $7.74 \pm 14.51$ days), as a result of a low number of the senior surgeon and complicated case referrals from other Hospitals; which will contribute for overall PLOS. This is similar to another study report from the low-income country; low physician-to-case ratio [5]. The second reason might be due to the difference in disease prevalence like burn patients contributed to longer hospitalization. This should gate attention from stakeholders because reducing hospitalization can reduce extra cost, risk of HAI, and increase productivity as a result of early discharge.

On the other hand, female gender, emergency admission, presence of Poly-pharmacy, and the presence of sepsis or in-hospital bloodstream infection were found to be independent predictors of in-hospital death at JUMC. Other studies showed that After adjusting for all co-morbidities, female gender $[20,28]$ while in contrast male gender $[11,21]$ and emergency surgery $[8,10,11,21]$, development of in-hospital complications [7, 17, 18, 22], sepsis [25] was an independent predictor for in-hospital 
Table 3 Chi-square test for in-hospital mortality among patients admitted to the surgery ward of JUMC, Ethiopia

\begin{tabular}{|c|c|c|c|c|}
\hline \multirow[t]{2}{*}{ Predictor Variables } & \multirow[t]{2}{*}{ Categories } & \multicolumn{2}{|c|}{ The outcome variable (in-hospital death) } & \multirow[t]{2}{*}{$p$-value } \\
\hline & & No $(\%)$ & Yes (\%) & \\
\hline \multirow[t]{2}{*}{ Sex } & Male & $174(97.2)$ & $5(2.8)$ & 0.036 \\
\hline & Female & $82(91.1)$ & $8(8.9)$ & \\
\hline \multirow[t]{2}{*}{ Age } & age of 18 to 40 & $142(94.0)$ & $9(6.0)$ & 0.329 \\
\hline & age of $>40$ & $114(96.6)$ & $4(3.4)$ & \\
\hline \multirow[t]{2}{*}{ Residence } & Rural & $143(96.0)$ & $6(4.0)$ & 0.492 \\
\hline & Urban & $113(94.2)$ & $7(5.8)$ & \\
\hline \multirow[t]{2}{*}{ Smoking status } & No & $226(95.4)$ & $11(4.6)$ & 0.658 \\
\hline & Yes & $30(93.8)$ & $2(6.2)$ & \\
\hline \multirow[t]{2}{*}{ ASA class } & ASA class I-II & $198(96.1)$ & $8(3.9)$ & 0.191 \\
\hline & ASA class III-IV & $58(92.1)$ & $5(7.9)$ & \\
\hline \multirow[t]{2}{*}{ Co-morbid condition } & No & $156(98.1)$ & $3(1.9)$ & 0.007 \\
\hline & Yes & $100(90.9)$ & $10(9.1)$ & \\
\hline \multirow[t]{2}{*}{ type of admission } & Elective & $136(98.6)$ & $2(1.4)$ & 0.008 \\
\hline & Emergency & $120(91.6)$ & $11(8.4)$ & \\
\hline \multirow[t]{2}{*}{ CDC wound class } & class 1 & $48(100)$ & $0(0)$ & 0.134 \\
\hline & class II-IV & $208(94.1)$ & $13(5.9)$ & \\
\hline \multirow[t]{2}{*}{ Poly-pharmacy status } & No & $221(97.4)$ & $6(2.6)$ & 0.001 \\
\hline & Yes & $35(83.3)$ & $7(16.7)$ & \\
\hline \multirow[t]{2}{*}{ Charlson $\mathrm{Cl}$} & $\mathrm{CCl}$ of 0 (no co-morbid) & $91(93.8)$ & $6(6.2)$ & 1.00 \\
\hline & $\mathrm{CCl}$ of $>1$ (yes co-morbid) & $165(95.9$ & $7(4.1)$ & \\
\hline \multirow[t]{3}{*}{ Amount of blood loss during surgery } & $<1500 \mathrm{ml}$ & $150(96.8)$ & $5(3.2)$ & 0.187 \\
\hline & $\geq 1500 \mathrm{ml}$ & $3(75.0)$ & $1(25.0)$ & \\
\hline & unknown (not recorded) & $103(93.6)$ & $7(6.4)$ & \\
\hline \multirow[t]{2}{*}{ Overall LOS } & $\leq 7$ days & $37(94.9)$ & $2(5.1)$ & 1.00 \\
\hline & $>7$ days & $219(95.2)$ & $11(4.8)$ & \\
\hline \multirow[t]{2}{*}{ After surgery LOS } & $\leq 7$ days & 65 (95.6) & $3(4.4)$ & 1.00 \\
\hline & $>7$ days & $191(95.0)$ & $10(5.0)$ & \\
\hline \multirow[t]{2}{*}{ Before surgery LOS } & $\geq 7$ days & $187(94.4)$ & $11(5.6)$ & 0.524 \\
\hline & $>7$ days & $69(97.2)$ & $2(2.8)$ & \\
\hline \multirow[t]{3}{*}{ duration of surgery } & $\leq 1 \mathrm{~h}$ & $81(95.3)$ & $4(4.7)$ & 0.994 \\
\hline & $>1 \mathrm{~h}$ & $133(95.0)$ & $7(5.0)$ & \\
\hline & Not recorded & $42(95.5)$ & $2(4.5)$ & \\
\hline \multirow[t]{2}{*}{ Right selection + dose + timing + duration + route of SAP } & All criteria correct & $47(88.7)$ & $6(11.3)$ & 0.025 \\
\hline & At least one criteria not correct & $209(96.8)$ & $7(3.2)$ & \\
\hline \multirow[t]{2}{*}{ Total number of antibiotic exposure } & $\leq 2$ antibiotic exposure & $200(97.1)$ & $6(2.9)$ & 0.015 \\
\hline & $>2$ antibiotic exposure & $56(88.9)$ & $7(11.1)$ & \\
\hline \multirow[t]{2}{*}{ HAP } & No & $251(95.8)$ & $11(4.2)$ & 0.329 \\
\hline & Yes & $5(71.4)$ & $2(28.6)$ & \\
\hline \multirow[t]{2}{*}{ Sepsis } & No & $247(96.9)$ & $8(3.1)$ & $<0.0001$ \\
\hline & Yes & $9(64.3)$ & $5(35.7)$ & \\
\hline \multirow[t]{2}{*}{ SSI } & No & $213(95.1)$ & $11(4.9)$ & 1.00 \\
\hline & Yes & 43 (95.6) & $2(4.4)$ & \\
\hline
\end{tabular}


Table 4 Bivariate analysis for PLOS among patients admitted to the surgical ward of JUMC, Ethiopia

\begin{tabular}{|c|c|c|c|c|c|}
\hline \multirow[t]{2}{*}{ Predictor Variables } & \multirow[t]{2}{*}{ Categories } & \multicolumn{2}{|c|}{ The outcome variable (PLOS) $>$ 75th percentile ( $\geq 33$ days) } & \multirow[t]{2}{*}{${ }^{* *} p$-value } & \multirow[t]{2}{*}{${ }^{*} p$-value } \\
\hline & & No (\%) & Yes (\%) & & \\
\hline \multirow[t]{2}{*}{ Sex } & Male & $146(81.6)$ & $33(18.4)$ & 0.169 & 0.000 \\
\hline & Female & $55(61.1)$ & $35(38.9)$ & & \\
\hline \multirow[t]{2}{*}{ Place of residence } & Rural & $110(73.8)$ & $39(26.2)$ & 0.547 & 0.706 \\
\hline & Urban & $91(75.8)$ & $29(24.2)$ & & \\
\hline \multirow[t]{4}{*}{ Level of monthly income } & no constant income & $33(70.2)$ & $14(29.8)$ & 0.291 & 0.396 \\
\hline & $<1500$ & $67(70.5)$ & $28(29.5)$ & & \\
\hline & $1500-6000$ & $81(79.4)$ & $21(20.6)$ & & \\
\hline & $>6000$ & $20(80.0)$ & $5(20.0)$ & & \\
\hline \multirow[t]{2}{*}{ Smoking status } & No & $173(73.0)$ & $64(27.0)$ & 0.522 & 0.076 \\
\hline & Yes & $28(87.5)$ & $4(12.5)$ & & \\
\hline \multirow[t]{2}{*}{ Health care cost coverage } & Self & $171(76.7)$ & $52(23.3)$ & 0.023 & 0.103 \\
\hline & Free (gov't) & $30(65.2)$ & $16(34.8)$ & & \\
\hline \multirow[t]{2}{*}{ Co-morbid condition } & No & $117(73.6)$ & $42(26.4)$ & 0.443 & 0.606 \\
\hline & Yes & $84(76.4)$ & $26(23.6)$ & & \\
\hline \multirow[t]{2}{*}{ Burn-related surgery } & No & $194(76.1)$ & $61(23.9)$ & 0.043 & 0.036 \\
\hline & Yes & $7(50)$ & $7(50)$ & & \\
\hline \multirow[t]{2}{*}{ Presence of cancer } & No & $173(77.6)$ & $50(22.4)$ & 0.028 & 0.018 \\
\hline & Yes & $28(60.9)$ & $18(39.1)$ & & \\
\hline \multirow[t]{2}{*}{ Presence of trauma } & No & $160(72.4)$ & $61(27.6)$ & 0.873 & 0.060 \\
\hline & Yes & $41(85.4)$ & $7(14.6)$ & & \\
\hline \multirow[t]{2}{*}{ Presence of any chronic disease } & No & $154(73.3)$ & $56(26.7)$ & 0.221 & 0.323 \\
\hline & Yes & $47(79.7)$ & $12(20.3)$ & & \\
\hline \multirow[t]{2}{*}{ Type of admission } & Elective & $95(68.8)$ & $43(31.2)$ & 0.864 & 0.023 \\
\hline & Emergency & $106(80.9)$ & $25(19.1)$ & & \\
\hline \multirow[t]{2}{*}{ Poly-pharmacy } & No & $169(74.4)$ & $58(25.6)$ & 0.861 & 0.811 \\
\hline & Yes & $32(76.2)$ & $10(23.8)$ & & \\
\hline \multirow[t]{2}{*}{ In-hospital SSI } & No & $173(77.2)$ & $51(22.8)$ & 0.244 & 0.035 \\
\hline & Yes & $28(62.2)$ & 17 (37.8) & & \\
\hline \multirow[t]{2}{*}{ In-hospital sepsis } & No & $191(74.9)$ & $64(25.1)$ & 0.366 & 0.771 \\
\hline & Yes & $10(71.4)$ & $4(28.6)$ & & \\
\hline \multirow[t]{2}{*}{ HAP } & No & $196(74.8)$ & $66(25.2)$ & 0.887 & 1 \\
\hline & Yes & $5(71.4)$ & $2(28.6)$ & & \\
\hline \multirow[t]{2}{*}{ Age (years) } & 18 to 40 & $115(76.2)$ & $36(23.8)$ & 0.188 & 0.539 \\
\hline & $>40$ & $86(72.9)$ & $32(27.1)$ & & \\
\hline \multirow[t]{3}{*}{ Duration of surgery (hrs.) } & $\leq 1$ & $57(67.1)$ & $28(32.9)$ & 0.391 & 0.083 \\
\hline & $>1$ & $107(76.4)$ & 33 (23.6) & 0.678 & \\
\hline & Not recorded & $37(84.1)$ & $7(15.9)$ & 0.172 & \\
\hline \multirow[t]{2}{*}{ Appropriate use of SAP } & Yes & $35(66.0)$ & $18(34.0)$ & 0.404 & 0.105 \\
\hline & No & $166(76.9)$ & $50(23.1)$ & & \\
\hline \multirow[t]{2}{*}{ Total number of antibiotic exposure } & $\leq 2$ antibiotic exposure & $165(80.1)$ & $41(19.9)$ & 0.017 & 0.000 \\
\hline & $>2$ antibiotic exposure & $36(57.1)$ & $27(42.9)$ & & \\
\hline ASA class & | to || & $150(72.8)$ & $56(27.2)$ & 0.499 & 0.193 \\
\hline & III to IV & $51(81.0)$ & $12(19.0)$ & & \\
\hline
\end{tabular}


Table 4 Bivariate analysis for PLOS among patients admitted to the surgical ward of JUMC, Ethiopia (Continued)

\begin{tabular}{|c|c|c|c|c|c|}
\hline \multirow[t]{2}{*}{ Predictor Variables } & \multirow[t]{2}{*}{ Categories } & \multicolumn{2}{|c|}{ The outcome variable (PLOS) > 75th percentile ( $\geq 33$ days) } & \multirow[t]{2}{*}{${ }^{* *} p$-value } & \multirow[t]{2}{*}{${ }^{*} p$-value } \\
\hline & & No (\%) & Yes (\%) & & \\
\hline \multirow[t]{2}{*}{ CDC wound class } & । & $34(70.8)$ & $14(29.2)$ & 0.047 & 0.494 \\
\hline & II to IV & $167(75.6)$ & $54(24.4)$ & & \\
\hline \multirow[t]{2}{*}{ Charlson $\mathrm{Cl}$ score } & Zero & $70(72.2)$ & $27(27.8)$ & 0.303 & 0.469 \\
\hline & $>1$ & $131(76.2)$ & $41(23.8)$ & & \\
\hline \multirow[t]{2}{*}{ Before surgery LOS (days) } & $\leq 7$ & $163(82.3)$ & $35(17.7)$ & 0.000 & 0.000 \\
\hline & $>7$ & $38(53.5)$ & $33(46.5)$ & & \\
\hline \multirow[t]{3}{*}{ Number of co-morbidity } & Zero & $117(73.6)$ & $42(26.4)$ & & 0.626 \\
\hline & 1 to 2 & 76 (77.6) & $22(22.4)$ & 0.248 & \\
\hline & $\geq 3$ & $8(66.7)$ & $4(33.3)$ & 0.248 & \\
\hline
\end{tabular}

${ }^{*} p$ value of chi-square, ${ }^{* *} p$-value for binary logistic regression analysis

mortality $[8,28]$, but, there was no clear reason for the gender-related increase in mortality. The gender-related discrepancy in predicting mortality might be due to the difference in baseline disease or type of operation (general surgery- coronary artery bypass graft surgery- thoracic surgery) respectively. The reason for emergency surgery related to more death is attributable to a complicated case and less time for preoperative care. Besides, the polypharmacy related more mortality is attributable to multiple diseases and/ or complicated cases that might directly or indirectly contribute to death.

Even though there is no consistent definition of prolonged length of hospital stay (greater than median LOS [3], 50th [4], 75th \& 90th [2] or 95th [1] percentile was used in different studies), it is usually used as a measure of quality indicators and efficient resource utilization [1, 3], yet imperfect proxy for quality [4]. It is common for surgical patients to have PLOS because of different reasons [1]. This issue was true for surgical patients admitted in JUMC; PLOS was $25.3 \%$ with 75 th percentile; at least 33 days of stay. Even though PLOS definition is different 50th vs. 75th percentile, PLOS was in line with another study (27.7\%) had a hospital stay of at least 8 days [4]. In contrary, ours is higher than PLOS of $23.1 \%$ with 95th percentile but, the cut of point is almost similar to our study; at least 34 days of stay [1] and the 75th and 90th percentile length of stay (LOS) were 9 and 16 days, respectively which is almost less by half [2] than that of JUMC. Because developing countries have many obstacles, which hinder quality surgical care [9].

In addition, female gender, Health care cost coverage by government, burn-related surgery, presence of cancer, $>2$ total number of antibiotic exposure, and $>7$ days waiting for surgery were the independent predictors for

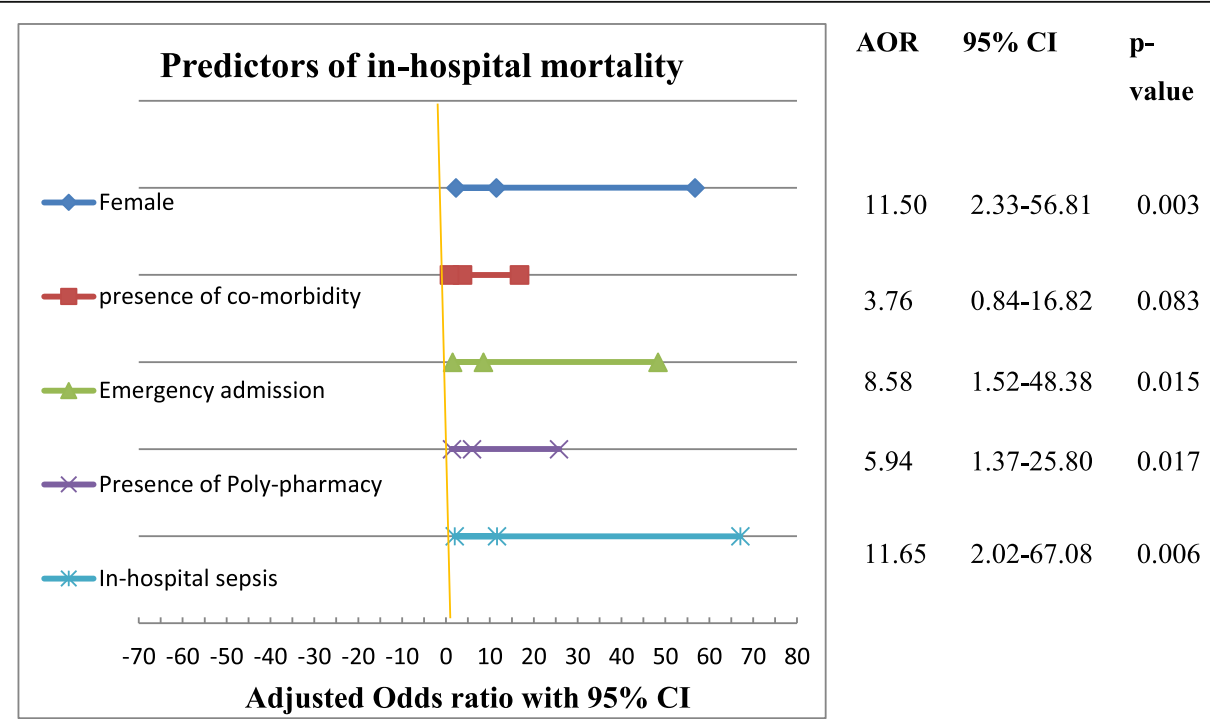

Fig. 2 Forest plot describing the result of multivariate analysis for in-hospital mortality among patients admitted to the surgical ward of JUMC, Ethiopia. N.B: AOR- Adjusted odds ratio, $\mathrm{Cl}$-Confidence interval 


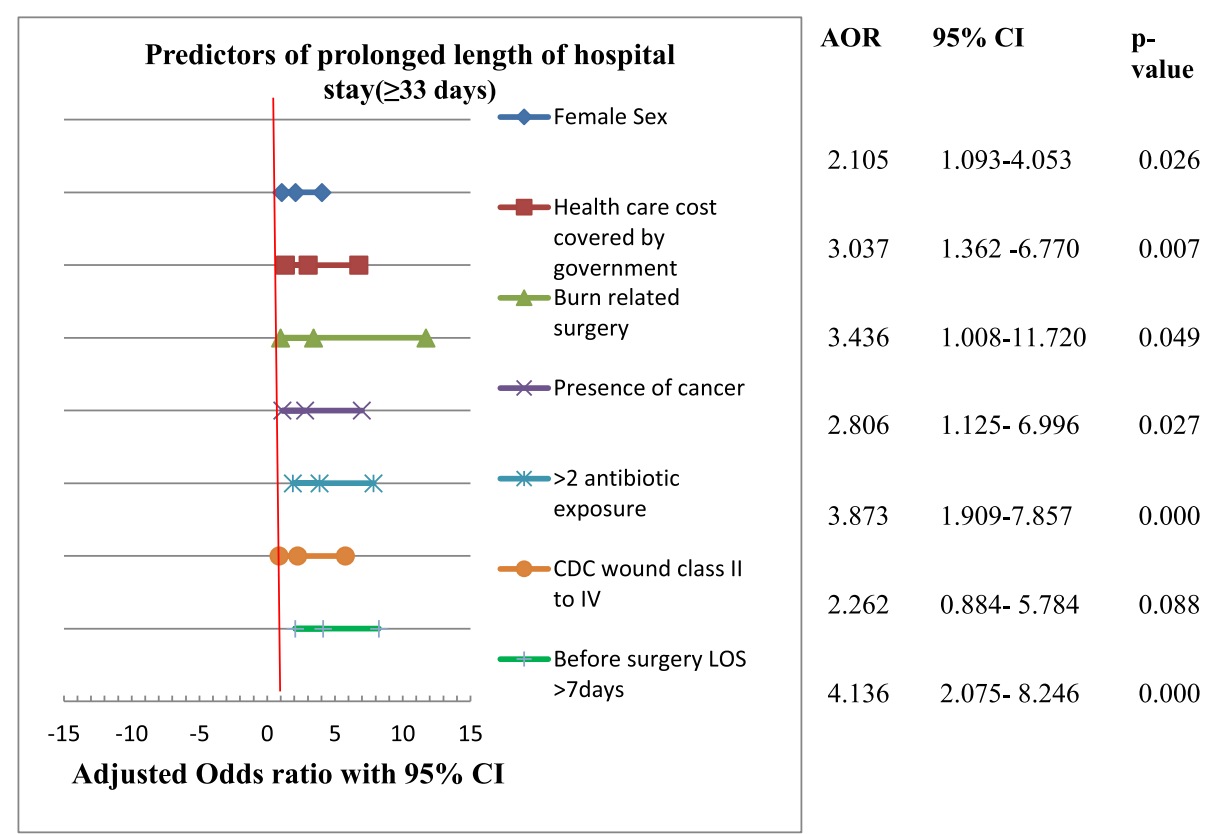

Fig. 3 Forest plot describing the result of multivariate analysis for PLOS among patients admitted to the surgical ward of JUMC, Ethiopia. N.B: LOS- length of hospital stay, PLOS- Prolonged length of hospital stay, AOR-Adjusted odds ratio, 95\% C.I for multivariate logistic regression

PLOS among the study participants. In contrast to our study finding, the male gender was found as independent predictors for PLOS [1]. There was no clear reason for gender as a predictor of PLOS but, the reason for female being as independent predictors in our case was as a result of burn-related surgery contributed for a longer stay for awaiting graft for a longer period than other elective surgery. Again patients with burn-related surgery were female patients (as evidenced by our data 3.9\% male versus $7.8 \%$ female (Table 2)); who pass their time near the fire for cooking. There were different predictors for PLOS which again contributed to in-hospital complications like HAI (sepsis, SSI) [2] and PLOS was contributed for 3 fold in-hospital mortality [1], on top of this preoperative patient and health facility-related factors are the independent predictors for PLOS [3]. There was no clear reason why patients whose health care cost covered by the government stay more in hospital than self payer at JUMC. This might be those patients are economically disadvantaged, for example, if the same medication for operation is ordered and unavailable in the hospital Pharmacy, they have to wait till medication is available (especially for elective cases) because they cannot buy from private Pharmacy (Table 1). This result was in line with other studies where low socio-economic status is independent predictors for PLOS [1].

The limitation of this study was that the use of consecutive sampling techniques (non-probability) than that of the probability sampling technique, owing to the cost for data collectors to get the total patients within a short period. Second, being single-center study. We hope future research will solve this issue.

\section{Conclusion and recommendations}

Even though the mortality rate at JUMC is within an acceptable range relative to study from a developing country, yet it was higher compared to the studies from developed countries. The prolonged length of hospital stay (PLOS $\geq 33$ days) was extremely higher than the previous reports. Besides these, the study also revealed a high rate of hospital-acquired infection (sepsis and HAP) during the study period, which has been contributing to in-hospital mortality. After adjusting for other variables, female gender, emergency surgery, presence of Poly-pharmacy, and presence of in-hospital sepsis were independent predictors for in-hospital mortality. Besides, female gender, Health care cost coverage by government, burn-related surgery, presence of cancer, $>2$ total number of antibiotic exposure, and $>7$ days waiting for surgery were the independent predictors for PLOS.

Therefore, in the study area, sepsis warrants great attention to improve patients' treatment outcomes or reduce in-hospital mortality. Based on the independent predictors for PLOS, patient's safety and quality of care could be improved by decreasing the waiting time for surgery, and other modifiable factors. This may increase productivity, access to surgery, and reduce person-bedday as a result of early discharge. 


\section{Abbreviations}

ASA: American Society of Anesthesiology; CCl: Charlson co-morbidity index; CDC: The Centers for Disease Control and Prevention; HAl: Hospital-acquired infection; HAP: Hospital-acquired pneumonia; JUMC: Jimma University Medical Center; LMIC: Low and middle-income country; PLOS: Prolonged length of hospital stay; SAP: Surgical Antimicrobial Prophylaxis; SSI: surgical site infection

\section{Acknowledgements}

First of all, we want to thank our GOD for his strength, wisdom, and protection in our journey and giving us the resilience, courage and hope to work hard and go through the tiring process of putting this work together, though it never seemed like it could come to an end. In addition, we would like to express our heartfelt appreciation to Jimma University for funding this study and to data collectors, study participants and all individuals who directly or indirectly contributed to the quality of this research.

\section{Authors' contributions}

Conceptualization and fund acquisition: GM. Supervising, project administration, study design and formal analysis: GM, BB, GT, \& TM. Investigation: GM, TM. Methodology: GM, TM. Writing-original draft: GM. Writing review \& editing: GM, BB, GT, \& TM. All authors read and approved the final manuscript.

\section{Funding}

Jimma University funded this study as graduate research. The funder has no role in the study design, data collection, and analysis, decision to publish, or preparation of the manuscript.

\section{Availability of data and materials}

The datasets used and/or analysed during the current study are available from the corresponding author on reasonable request.

\section{Competing interests}

The authors declare that they have no competing interests.

\section{Author details}

'Department of Pharmacy, Clinical Pharmacy Unit, Ambo University, Ambo, Ethiopia. ${ }^{2}$ Department of Public Health, Nutrition Course Unit, Ambo University, Ambo, Ethiopia. ${ }^{3}$ School of Pharmacy, Department of Clinical Pharmacy, Jimma University, Jimma, Ethiopia.

Received: 9 December 2019 Accepted: 22 May 2020 Published online: 16 June 2020

\section{References}

1. Marfil-Garza BA, Belaunzarán-Zamudio PF, Gulias-Herrero A, Zuñiga AC, Caro-Vega Y, Kershenobich-Stalnikowitz D, et al. Risk factors associated with prolonged hospital length-of-stay: 18-year retrospective study of hospitalizations in a tertiary healthcare center in Mexico. PLoS One. 2018; 13(11):e0207203.

2. Krell RW, Girotti ME, Dimick JB. Extended length of stay after surgery: complications, inefficient practice, or sick patients? JAMA Surg. 2014;149(8): 815-20.

3. Lee SY, Lee S-H, Tan JH, Foo HS, Phan PH, Kow AW, et al. Factors associated with prolonged length of stay for elective hepatobiliary and neurosurgery patients: a retrospective medical record review. BMC Health Serv Res. 2018; 18(1):5.

4. Dasenbrock HH, Liu KX, Devine CA, Chavakula V, Smith TR, Gormley WB, et al. Length of hospital stay after craniotomy for tumor: a National Surgical Quality Improvement Program analysis. Neurosurg Focus. 2015;39(6):E12.

5. Weiser TG, Regenbogen SE, Thompson KD, Haynes AB, Lipsitz SR, Berry WR, et al. An estimation of the global volume of surgery: a modelling strategy based on available data. Lancet. 2008;372(9633):139-44.

6. MA S. Prevalence and risk factors associated with post operative infections in the Limbe regional Hospital of Cameroon. Open Surg J. 2014;8(1):1-8.

7. Kennedy J, Van Rij A, Spears G, Pettigrew R, Tucker I. Polypharmacy in a general surgical unit and consequences of drug withdrawal. $\mathrm{Br} J \mathrm{Clin}$ Pharmacol. 2000;49(4):353-62.
8. Alves A, Panis Y, Mathieu P, Mantion G, Kwiatkowski F, Slim K. Postoperative mortality and morbidity in French patients undergoing colorectal surgery: results of a prospective multicenter study. Arch Surg. 2005;140(3):278-83.

9. Huynh C, Huynh MN. The Global Burden of Surgical Disease: An Analysis of Inaccessible Surgical Care in Low and Middle Income Countries; 2018.

10. Shah S, Hariharan U, Chawla R. Integrating perioperative medicine with anaesthesia in India: can the best be achieved? A review. Indian J Anaesthesia. 2019;63(5):338.

11. Biluts H, Bekele A, Kottiso B, Enqueselassie F, Munie T. In-patient surgical mortality in Tikur Anbessa hospital: a five-year review. Ethiop Med J. 2009; 47(2):135-42.

12. Biccard BM, Madiba TE, Kluyts H-L, Munlemvo DM, Madzimbamuto FD, Basenero A, et al. Perioperative patient outcomes in the African surgical outcomes study: a 7-day prospective observational cohort study. Lancet. 2018;391(10130):1589-98.

13. Burssa D, Teshome A, Iverson K, Ahearn O, Ashengo T, Barash D, et al. Safe surgery for all: early lessons from implementing a National GovernmentDriven Surgical Plan in Ethiopia. World J Surg. 2017;41(12):3038-45.

14. Tefera GM, Feyisa BB, Kebede TM. Antimicrobial use-related problems and their costs in surgery ward of Jimma University medical center: prospective observational study. PLoS One. 2019;14(5):1-15.

15. Lwanga SK, Lemeshow S, World HO. Sample size determination in health studies : a practical manual / S. K. Lwanga and S. Lemeshow. Geneva: World Health Organization; 1991.

16. Abula T, Kedir M. The pattern of antibiotic usage in surgical in-patients of a teaching hospital, Northwest Ethiopia. Ethiop J Health Dev. 2004;18(1):35-8.

17. Thompson DA, Makary MA, Dorman T, Pronovost PJ. Clinical and economic outcomes of hospital acquired pneumonia in intra-abdominal surgery patients. Ann Surg. 2006;243(4):547.

18. von Dossow V, Rotard K, Redlich U, Hein OV, Spies CD. Circulating immune parameters predicting the progression from hospital-acquired pneumonia to septic shock in surgical patients. Crit Care. 2005;9(6):R662.

19. Young B, Ng TM, Teng C, Ang B, Tai HY, Lye DC. Nonconcordance with surgical site infection prevention guidelines and rates of surgical site infections for general surgical, neurological, and orthopedic procedures. Antimicrob Agents Chemother. 2011;55(10):4659-63.

20. Tamrat G, Osman M, Deyessa N, Taye M, Lett R, Bekele A. Delay of emergency surgical interventions in Ethiopia: patient and health system factors. East Central Afr J Surg. 2018;23(2):59-65.

21. Falcoz PE, Conti M, Brouchet $L$, Chocron S, Puyraveau M, Mercier M, et al. The Thoracic Surgery Scoring System (Thoracoscore): risk model for inhospital death in 15,183 patients requiring thoracic surgery. J Thorac Cardiovasc Surg. 2007;133(2):325-32 e1.

22. Merani S, Payne J, Padwal RS, Hudson D, Widder SL, Khadaroo RG. Predictors of in-hospital mortality and complications in very elderly patients undergoing emergency surgery. World J Emerg Surg. 2014;9(1):43.

23. Gutierrez-Morlote J, Llorca J. Ibanez de Elejalde E, Lobato a, San Jose JM. Predictors of mortality in patients undergoing surgery for ruptured aortic aneurysm. Vasa. 2002;31(4):265-8.

24. Hannan EL, Racz MJ, Jones RH, Gold JP, Ryan TJ, Hafner J-P, et al. Predictors of mortality for patients undergoing cardiac valve replacements in New York state. Ann Thorac Surg. 2000;70(4):1212-8. https://doi.org/10.1016/ s0003-4975(00)01968-8.

25. Stahlschmidt A, Novelo B, Freitas LA, Passos SC, Dussán-Sarria JA, Félix EA, et al. Predictors of in-hospital mortality in patients undergoing elective surgery in a university hospital: a prospective cohort. Rev Bras Anestesiol. 2018;68(5):492-8.

26. Turrentine FE, Wang H, Simpson VB, Jones RS. Surgical risk factors, morbidity, and mortality in elderly patients. J Am Coll Surg. 2006:203(6):865-77.

27. Gabriel RA, Alison M, Schmidt UH, Dutton RP, Urman RD. Time of day is not associated with increased rates of mortality in emergency surgery: an analysis of 49,196 surgical procedures. J Clin Anesth. 2018;46:85-90.

28. Blankstein R, Ward RP, Arnsdorf M, Jones B, Lou Y-B, Pine M. Female gender is an independent predictor of operative mortality after coronary artery bypass graft surgery: contemporary analysis of 31 Midwestern hospitals. Circulation. 2005;112(9_supplement):I-323-I-7.

\section{Publisher's Note}

Springer Nature remains neutral with regard to jurisdictional claims in published maps and institutional affiliations. 